\title{
Triangulation Applied to the Intra-European Union Tomato Market
}

\author{
Jaime De Pablo Valenciano $\mathbb{D}^{1},{ }^{1}$ José Antonio Torres Arriaza, ${ }^{2}$ Juan Uribe-Toril $\mathbb{D}^{1}{ }^{1}$ \\ and José Luis Ruiz-Real ${ }^{1}$ \\ ${ }^{1}$ Faculty of Economics and Business, University of Almeria, Ctra. De Sacramento, s/n, Almería 04120, Spain \\ ${ }^{2}$ Faculty of Computer Science, University of Almeria, Ctra. De Sacramento, s/n, Almería 04120, Spain \\ Correspondence should be addressed to Jaime De Pablo Valenciano; jdepablo@ual.es
}

Received 3 March 2020; Accepted 1 May 2020; Published 15 May 2020

Guest Editor: François Pérès

Copyright (C) 2020 Jaime De Pablo Valenciano et al. This is an open access article distributed under the Creative Commons Attribution License, which permits unrestricted use, distribution, and reproduction in any medium, provided the original work is properly cited.

\begin{abstract}
An understanding of the intracommunity trade is essential for the agents involved in the fresh tomato market (farmers, entrepreneurs, public administrations, and consumers). The purpose of this paper is to analyze the interdependent relationships between exporting and importing countries within the European Union for a specific product such as fresh tomatoes and thus understand which have been the key countries in three specific years (2002-2007-2017). The methodology used to study the interrelationships of trade flows in the countries of the European Union (EU) is that of triangulation by means of the Leontief input-output model. Artificial intelligence techniques are used to process and triangulate the data based on pathfinding techniques using a cost function. The triangulation results have created a hierarchy of countries (suppliers and customers). This type of methodology has not been applied to the field of foreign trade. The results show that Netherlands and Spain are key countries in intracommunity trade as they have a strong impact both with regard to their exports and their imports and are fundamental when analyzing the growth of specific sectors and how they are able to stimulate the economies of other countries.
\end{abstract}

\section{Introduction}

According to Leontief [1], input-product matrices are a fundamental tool for studying the interrelationships of economic structures and for finding the best way to activate the economy. In particular, there has been a long tradition of using them for establishing hierarchies in economic structures, although their use has proven to be very complex, since it is impossible to arrive at a strictly hierarchical structure in view of the persistence of both direct (binary) and indirect induction cycles (circular interrelations). Therefore, it is necessary to reorganize the branches that form the whole economic structure in order to preserve the hierarchical classification to the extent possible.

Input-out triangulation studies are based on the idea of inter-industrial transactions can be recorded in a matrix between the origin (in our case, exporting countries) and destination (importing countries).
The years analyzed in this study are 2002, 2007, and 2017. The reason for choosing these years is to consider whether the economic and financial crisis that began in 2007 and that affected the economies of the European Union had an impact on the hierarchy of tomato producing countries and their customers with regard to intracommunity trade. It should be borne in mind that there is a close relationship between exporting countries, importing countries and several other countries that act as forwarders within the intra-EU market itself.

As can be seen in Table 1, in 2017, the main intracommunity destinations and importing countries were Germany, the United Kingdom, France, and the Netherlands. These four countries account for $57.18 \%$ of the total. In 2002, the participation was $73.95 \%$. This reduction is due to the fact that Poland, Spain, Italy, and Lithuania have increased their participation as import destinations. 
TABLE 1: Evolution in the participation percentage of importing countries in the intra-EU tomato market (2002-2007-2017).

\begin{tabular}{|c|c|c|c|c|}
\hline \multicolumn{5}{|c|}{ Participation of importing countries (\%) } \\
\hline & 2002 & 2007 & 2017 & Var \\
\hline Austria & 1.82 & 2.01 & 1.86 & 0.04 \\
\hline Belgium & 2.96 & 2.76 & 3.72 & 0.76 \\
\hline Bulgaria & 0.01 & 0.05 & 0.8 & 0.87 \\
\hline Cyprus & 0.00 & 0.01 & 0.02 & 0.02 \\
\hline Czech Republic & 3.01 & 3.41 & 3.50 & 0.49 \\
\hline Denmark & 1.09 & 1.31 & 1.36 & 0.27 \\
\hline Estonia & 0.35 & 0.40 & 0.52 & 0.17 \\
\hline Finland & 0.91 & 0.86 & 1.14 & 0.23 \\
\hline France & 11.20 & 10.44 & 9.02 & -2.18 \\
\hline Germany & 34.87 & 29.87 & 28.72 & -6.15 \\
\hline Greece & 0.15 & 0.28 & 0.26 & 0.11 \\
\hline Hungary & 0.33 & 0.61 & 0.49 & 0.16 \\
\hline Ireland & 1.04 & 1.08 & 1.11 & 0.07 \\
\hline Italy & 2.94 & 4.23 & 4.51 & 1.58 \\
\hline Latvia & 0.53 & 0.57 & 1.06 & 0.53 \\
\hline Lithuania & 0.34 & 0.61 & 4.06 & 3.72 \\
\hline Luxembourg & 0.20 & 0.22 & 0.20 & 0.00 \\
\hline Malta & 0.00 & 0.02 & 0.05 & 0.05 \\
\hline Netherlands & 11.89 & 9.13 & 5.81 & -6.07 \\
\hline Poland & 2.15 & 2.58 & 5.30 & 3.16 \\
\hline Portugal & 2.32 & 1.15 & 1.29 & -1.03 \\
\hline Romania & 0.02 & 0.17 & 1.27 & 1.26 \\
\hline Slovakia & 0.40 & 0.66 & 1.10 & 0.70 \\
\hline Slovenia & 0.31 & 0.29 & 0.51 & 0.20 \\
\hline Spain & 2.10 & 5.24 & 5.08 & 2.99 \\
\hline Sweden & 3.08 & 3.58 & 3.51 & 0.43 \\
\hline United Kingdom & 15.99 & 18.46 & 13.62 & -2.37 \\
\hline
\end{tabular}

Source: European Commission. Documents from the forecast working group. https://ec.europa.eu/agriculture/fruit-and-vegetables/productreports/tomatoes_en.

With regard to the countries of origin (Table 2), in 2017, the Netherlands and Spain represent $70.33 \%$ of the total market, while in 2002 , this figure rose to $76.03 \%$. The lead exporting country in 2002 was Spain although it has subsequently been replaced by the Netherlands.

The purpose of this paper is to analyze the interdependent relations of the transactions between exporting and importing countries of different member states of the EU, in a specific product market such as that of tomatoes and to understand which were the key countries in three specific years (2002-2007-2017). This vegetable is considered the most important fresh products within the EU market, both in terms of production and commercialization.

\section{Materials and Methods}

In the analysis of relationships between data, the scientific literature is extensive and varied. DEMATEL-based approaches to the analysis of financial risks in banks are current, as demonstrated in the works of [2-4]. The use of Influence Network Relation Map (INMR) is a working tool that has been proven in the analysis of complex processes of sustainable urbanism, as shown by the works of $[5,6]$. Against this, the analysis of economic variables by input-output table triangulation has been for many
TABLE 2: Evolution in the participation percentage of exporting countries in the intra-EU tomato market (2002-2007-2017).

\begin{tabular}{lcccc}
\hline \multicolumn{5}{c}{ Participation of exporting countries (\%) } \\
& 2002 & 2007 & 2017 & Var \\
\hline Austria & 0.26 & 0.55 & 0.32 & 0.06 \\
Belgium & 8.31 & 8.31 & 7.82 & -0.50 \\
Czech Republic & 0.00 & 0.27 & 0.29 & 0.29 \\
France & 5.52 & 5.00 & 8.81 & 3.29 \\
Germany & 1.35 & 1.58 & 0.71 & -0.65 \\
Italy & 5.37 & 3.88 & 3.96 & -1.41 \\
Netherlands & 29.95 & 33.60 & 36.08 & 6.13 \\
Poland & 0.00 & 2.46 & 1.35 & 1.35 \\
Portugal & 1.71 & 2.33 & 4.01 & 2.30 \\
Spain & 46.08 & 41.17 & 34.25 & -11.83 \\
Others & 1.44 & 0.85 & 2.41 & 0.97 \\
\hline
\end{tabular}

Source: European Commission. Documents from the forecast working group. https://ec.europa.eu/agriculture/fruit-and-vegetables/productreports/tomatoes_en.

years the preferred tool of economic researchers. Our work is an improvement on this last method, without diverting attention, in future studies, in the comparison with other procedures of analysis of relationships between variables.

The input-output methodology has been applied in various fields, including industry [7-13], energy [14], water $[15,16]$, price systems [17], structural changes $[18,19]$, and human capital [20], among others. It has also been used to analyze key sectors, such as the work by Haji [21] related to key sectors in Kuwait's productive structure, the article by Cassetti [22] which identifies sectors by transactions in different countries, and the work by Díaz et al. [23] who identify key sectors by means of multiplier, diffusion, topological hierarchy, technological level, diffusion of innovation, and polluting capacity.

To learn about the interdependent relationships within a matrix, it must be based on a structural analysis that presents the following situations (Figure 1):

(i) Total dependency or interdependency is defined as each sector depending on the rest of the sectors, acting as a supplier and receiver of inputs.

(ii) Interdependence occurs when some sectors depend on others, even if some can act independently.

(iii) Hierarchy corresponds to a nonreal situation but rather is obtained by rearranging of certain criteria. In the case of a perfectly triangular matrix, the sectors that are above and below the row corresponding to a given sector have very different relationships [24]. Those located below are suppliers of the sector, causing an increase in the final demand of their product which then generates indirect demands that are precipitated by the main diagonal of the matrix without affecting the sectors located above the sector in question. Those located above the row are considered to be customers. Any increase in demand corresponding to the output of any of them generates indirect demand for the output of the sector in question. 


\begin{tabular}{|c|c|c|c|c|}
\hline$\circ$ & 0 & 0 & 0 & 0 \\
\hline 0 & 0 & 0 & 0 & 0 \\
\hline$\circ$ & 0 & 0 & 0 & 0 \\
\hline$\circ$ & 0 & 0 & 0 & 0 \\
\hline 0 & 0 & 0 & 0 & 0 \\
\hline
\end{tabular}

O Intermediate demand greater than $1 / n$, where $n$ is the number of branches.

(a)

\begin{tabular}{|l|l|l|l|l|}
\hline$\circ$ & & & $\circ$ & $\circ$ \\
\hline$\circ$ & $\circ$ & $\circ$ & $\circ$ & \\
\hline & $\circ$ & $\circ$ & & \\
\hline$\circ$ & $\circ$ & & $\circ$ & \\
\hline$\circ$ & & $\circ$ & & 0 \\
\hline
\end{tabular}

O Intermediate demand greater than $1 / n$, where $n$ is the number of branches.

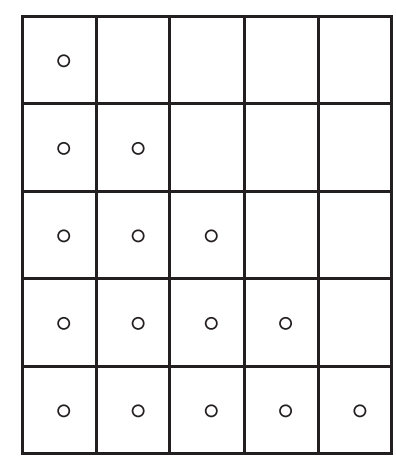

O Intermediate demand greater than $1 / n$, where $n$ is the number of branches.

(c)

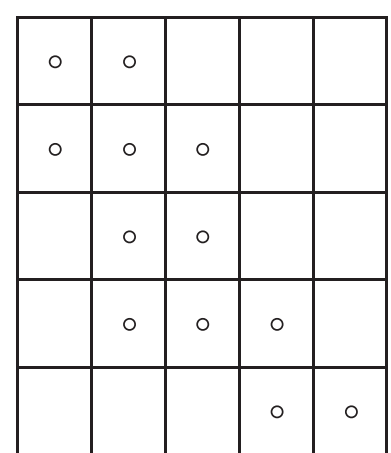

O Intermediate demand greater than $1 / n$, where $n$ is the number of branches.

(d)

FIgURE 1: Basic concepts of structural analysis: (a) interdependence; (b) independence; (c) hierarchy; (d) circularity.

(iv) Circularity is where perfect triangulation is not achieved and the asymmetry is broken due to another demand and supply sector or multiregional interdependence.

This study will focus on creating a hierarchy through the triangulation methodology. According to Korte and Oberhofer [25], this methodology performs, among others, the following tasks:

(i) Sheds light on the functioning of the economy from a structural point of view

(ii) Facilitates comparison between the economies of different countries and periods

(iii) Optimally influences cycle and growth

(iv) Makes matrix inversion easier

(v) Useful for forecasting and economic planning

This method of triangulation by means of input-output tables was pioneered by Korte and Oberhofer [25, 26] although it has since been subject to a number of variations [27-33]. Grötschel et al. [34] utilizes new polyhedral results for the triangulation problem in a linear programming cutting plane framework. Professor Göram Östblom [35] introduced the alternative approach of maximizing the sum of negative differences between the elements below and the symmetrical elements above the principal diagonal. A series of suboptimal solutions, converging to the optimal solutions, is proposed as an approximate solution for tables of large dimension.

In order to study the interrelationships of trade flows in the tomato market in EU countries, three matrices $(\mathrm{M} 11 \times 11)$ have been developed, namely, through the trade flows corresponding to 2002, 2007, and 2017 (Tables 3-5).

An outline of the trade flows can be seen in Table 6 . The columns correspond to imports (tons), and the rows correspond to exports (tons). The total sum of the transactions of the exporting and importing countries coincide. The data have been obtained from Eurostat [36] and from the reports of the European Working Group in "tomatoes" [37].
Once the table of commercial transactions is completed, the technical coefficients table (A) is retrieved. The components of this table represent the direct commercial effort carried out by country $i$ per unit of consumption of country $j$. The value of each of the coefficients would be $a_{i}$ ${ }_{j}=\mathrm{M}_{i j} / \mathrm{c}_{j}$.

From the matrix of coefficients, we develop the technological matrix which is the difference between the identity matrix and that of the technical coefficients. In a classic input-output analysis [1], (A) would be a technical matrix used to analyze the direct relationships between total demand (internal and external) and trade flows. The Leontief inverse matrix is defined as $\mathrm{B}=(\mathrm{I}-\mathrm{A})^{-1}$ (Tables 7-9).

To determine the hierarchy of specific countries according to the impact that they could have on a specific economic sector in other countries, Chenery-Watanabe coefficients have been traditionally used [38], but these have significant limitations [39]:

(a) They use the direct coefficients of the transaction matrix without taking into account the indirect effects

(b) The coefficients obtained represent measures without regard to their deviations

(c) These indices are not weighted

Given these limitations, another form of triangulation is proposed by means of artificial intelligence based on pathfinding techniques using cost functions.

The use of cost functions for the minimization of functions is a technique widely used in artificial intelligence, statistics, and other technical disciplines when it comes to solving an optimization problem iteratively where the gradient calculation of the cost function is used to determine the direction of modification of the problem resolution parameters.

There is extensive literature on this subject, whether it be generally about these techniques, their application, or as a way to optimize functions in economics [40-42]. The search for optimal paths has continued its development in 
TABle 3: Matrix of trade transactions 2002.

\begin{tabular}{lccccccccccc}
\hline & NL & ES & FR & BE & IT & DE & PT & PL & EL & UK & REU \\
\hline NL & $\mathbf{0}$ & 1429 & 20160 & 21558 & 21507 & 308731 & 1 & 66317 & 609 & 106501 & 195761 \\
ES & 202873 & 0 & 156883 & 21742 & 21915 & 204400 & 42676 & 270520 & & 183431 & 617299 \\
FR & 3182 & 2286 & $\mathbf{0}$ & 0 & 7629 & 27913 & 36 & 1361 & 382 & 5089 & 67692 \\
BE & 11519 & 1047 & 29495 & $\mathbf{0}$ & 1932 & 73583 & 56 & 28904 & 1007 & 4168 & 12625 \\
IT & 776 & 46 & 7375 & 1365 & $\mathbf{0}$ & 66118 & 0 & 36319 & 401 & 8886 & 124268 \\
DE & 13326 & 1889 & 5082 & 1106 & 4475 & $\mathbf{0}$ & 2675 & 193 & 1902 & 2607 & 7875 \\
PT & 0 & 34217 & 22 & 0 & 8 & 7 & $\mathbf{0}$ & 0 & 0 & 1022 & 26 \\
PL & 47 & 0 & 0 & 54 & 0 & 315 & 0 & $\mathbf{0}$ & 137 & 0 & 160347 \\
EL & 0 & 0 & 176 & 0 & 3 & 80 & 0 & 1000 & $\mathbf{0}$ & 93 \\
UK & 325 & 114 & 9 & 81 & 0 & 428 & 0 & 564 & 0 & $\mathbf{0}$ \\
REU & 856 & 0 & 129 & 12103 & 31 & 1319 & 0 & 15311 & 14 & 1415 & 6432 \\
\hline
\end{tabular}

NL, Netherlands; ES, Spain; FR, France; BE, Belgium; IT, Italy; DE, Germany; PT, Portugal; PL, Poland; EL, Greece; UK, United Kingdom; REU, rest EU.

TABLE 4: Matrix of trade transactions 2007.

\begin{tabular}{|c|c|c|c|c|c|c|c|c|c|c|c|}
\hline & NL & ES & FR & $\mathrm{BE}$ & IT & $\mathrm{DE}$ & $\mathrm{PT}$ & $\mathrm{PL}$ & EL & UK & REU \\
\hline NL & 0 & 7049 & 28488 & 22742 & 30278 & 376111 & 149 & 14499 & 3154 & 174265 & 173305 \\
\hline ES & 138203 & 0 & 128124 & 21177 & 24931 & 158701 & 29180 & 44742 & 7 & 159568 & 109599 \\
\hline FR & 6311 & 3716 & 0 & 22508 & 16189 & 49390 & 449 & 5308 & 571 & 8555 & 16172 \\
\hline $\mathrm{BE}$ & 21472 & 2701 & 44924 & 0 & 2102 & 60145 & 25 & 2005 & 3333 & 6123 & 10527 \\
\hline IT & 3759 & 210 & 8622 & 739 & $\mathbf{0}$ & 50398 & 7 & 2004 & 1674 & 14302 & 31319 \\
\hline $\mathrm{DE}$ & 14239 & 36 & 3855 & 0 & 6977 & 0 & 2801 & 7756 & 3678 & 16187 & 30254 \\
\hline PT & 0 & 205201 & 1341 & 0 & 160 & 7 & 0 & 0 & 0 & 1342 & 66 \\
\hline PL & 1210 & 546 & 2862 & 306 & 996 & 1768 & 0 & 0 & 2050 & 26832 & 37849 \\
\hline EL & 33 & 0 & 16 & 0 & 0 & 437 & 0 & 288 & 0 & 1613 & 1747 \\
\hline UK & 1595 & 474 & 747 & 0 & 0 & 338 & 0 & 32 & 0 & 0 & 5047 \\
\hline REU & 1038 & 94 & 359 & 1380 & 292 & 5044 & 0 & 796 & 312 & 1356 & $\mathbf{0}$ \\
\hline
\end{tabular}

NL, Netherlands; ES, Spain; FR, France; BE, Belgium; IT, Italy; DE, Germany; PT, Portugal; PL, Poland; EL, Greece; UK, United Kingdom; REU, rest EU.

TABLE 5: Matrix of trade transactions 2017.

\begin{tabular}{lccccccccccc}
\hline & NL & ES & FR & BE & IT & DE & PT & PL & EL & UK & REU \\
\hline NL & $\mathbf{0}$ & 14195 & 33206 & 39547 & 46763 & 415675 & 104 & 33665 & 154 & 176984 & 273235 \\
ES & 118008 & $\mathbf{0}$ & 150798 & 16385 & 37233 & 169804 & 32255 & 57324 & 16 & 143183 & 130053 \\
FR & 19488 & 5558 & $\mathbf{0}$ & 29545 & 20100 & 68153 & 626 & 16739 & 0 & 12319 & 30139 \\
BE & 24372 & 2289 & 57325 & $\mathbf{0}$ & 5395 & 47936 & 0 & 1306 & 689 & 7081 & 17081 \\
IT & 1759 & 695 & 6397 & 1401 & $\mathbf{0}$ & 35896 & 0 & 4141 & 1175 & 9759 & 43478 \\
DE & 4867 & 900 & 4670 & 5105 & 7804 & $\mathbf{0}$ & 1141 & 17888 & 1608 & 18296 & 34469 \\
PT & 216 & 58902 & 1883 & 118 & 411 & 0 & $\mathbf{0}$ & 599 & 0 & 2736 \\
PL & 524 & 4219 & 915 & 110 & 1057 & 2441 & 83 & $\mathbf{0}$ & 501 & 5806 & 107 \\
EL & 0 & 28 & 0 & 0 & 0 & 183 & 0 & 48 & $\mathbf{0}$ & 0 & 17803 \\
UK & 2387 & 1451 & 913 & 72 & 0 & 131 & 1 & 22 & 0 & $\mathbf{0}$ & 9785 \\
REU & 2725 & 179 & 158 & 535 & 247 & 4405 & 1 & 741 & 363 & 1117 & $\mathbf{0}$ \\
\hline
\end{tabular}

NL, Netherlands; ES, Spain; FR, France; BE, Belgium; IT, Italy; DE, Germany; PT, Portugal; PL, Poland; EL, Greece; UK, United Kingdom; REU, rest EU.

TABLE 6: Trade flows.

\begin{tabular}{|c|c|c|c|c|c|c|}
\hline & Country 1 & Country 2 & Country $n$ & $\mathrm{XI}$ & $\mathrm{ID}=\mathrm{C}+\mathrm{XE}$ & $\mathrm{DT}=\mathrm{XE}+\mathrm{XI}+\mathrm{C}$ \\
\hline Country 1 & M11 & M12 & M1n & $\mathrm{X} 1$ & ID1 & DT1 \\
\hline Country 2 & M21 & M22 & $\mathrm{M} 2 n$ & $\mathrm{X} 2$ & ID2 & DT2 \\
\hline Country $n$ & $\mathrm{M} n 1$ & $\mathrm{M} n 2$ & $\mathrm{M} n n$ & $\mathrm{X} n$ & IDn & $\mathrm{DT} n$ \\
\hline II & II1 & II 2 & $\mathrm{II} n$ & & & \\
\hline IE & IE2 & IE2 & $\mathrm{IE} n$ & & & \\
\hline $\mathrm{P}$ & $\mathrm{P} 1$ & $\mathrm{P} 2$ & $\mathrm{P} n$ & & & \\
\hline $\mathrm{C}$ & $\mathrm{C} 1$ & $\mathrm{C} 2$ & $\mathrm{Cn}$ & & & \\
\hline
\end{tabular}

$\mathrm{ID}=$ intermediate demand; $\mathrm{II}_{i}=$ imports from other EU countries (intra-EU) to country " $i$;" $\mathrm{IE}_{i}=$ imports from countries outside the EU to country "i;" $\mathrm{XI}_{i}=$ exports to other EU countries from country “ $i$;" $\mathrm{XE}_{i}=$ exports to countries outside the EU from country “ $i$;" $\mathrm{P}_{i}=$ production of country “ $i$;" $\mathrm{C}_{i}=$ apparent consumption of country "i;" $\mathrm{C}_{i}=\mathrm{P}_{i}-\mathrm{XI}_{i}-\mathrm{XE}_{i}+\mathrm{II}_{i}+\mathrm{IE}_{i}$. 
TABLE 7: Inverse matrix 2002.

\begin{tabular}{lccccccccccc}
\hline & NL & ES & FR & BE & IT & DE & PT & PL & EL & UK & REU \\
\hline NL & 1.08153 & 0.00227 & 0.03774 & 0.21442 & 0.02440 & 0.50196 & 0.01480 & 0.29490 & 0.00184 & 0.28758 & 0.09892 \\
ES & 1.88948 & 1.01532 & 0.26784 & 0.59621 & 0.06643 & 1.20549 & 0.47438 & 1.55313 & 0.00427 & 0.96260 & 0.46674 \\
FR & 0.03673 & 0.00174 & 1.00204 & 0.01074 & 0.00814 & 0.05834 & 0.00272 & 0.01941 & 0.00052 & 0.02343 & 0.02917 \\
BE & 0.11798 & 0.00125 & 0.04072 & 1.02594 & 0.00519 & 0.16167 & 0.00555 & 0.13963 & 0.00141 & 0.04321 & 0.02312 \\
IT & 0.02140 & 0.00029 & 0.01096 & 0.02241 & 1.00100 & 0.10651 & 0.00305 & 0.14302 & 0.00065 & 0.02852 & 0.05540 \\
DE & 0.12321 & 0.00222 & 0.01123 & 0.03469 & 0.00706 & 1.05952 & 0.02984 & 0.03814 & 0.00208 & 0.04035 & 0.01524 \\
PT & 0.04391 & 0.02359 & 0.00625 & 0.01386 & 0.00155 & 0.02802 & 1.01102 & 0.03609 & 0.00010 & 0.02485 & 0.01086 \\
PL & 0.00169 & 0.00001 & 0.00031 & 0.00679 & 0.00006 & 0.00203 & 0.00006 & 1.00438 & 0.00015 & 0.00073 & 0.05820 \\
EL & 0.00004 & 0.00000 & 0.00022 & 0.00010 & 0.00001 & 0.00016 & 0.00000 & 0.00370 & 1.00000 & 0.00024 & 0.00085 \\
UK & 0.00323 & 0.00009 & 0.00018 & 0.00161 & 0.00008 & 0.00224 & 0.00010 & 0.00325 & 0.00001 & 1.00092 & 0.00278 \\
REU & 0.02055 & 0.00015 & 0.00476 & 0.11018 & 0.00077 & 0.02282 & 0.00075 & 0.07406 & 0.00019 & 0.01027 & 1.03003 \\
\hline
\end{tabular}

NL, Netherlands; ES, Spain; FR, France; BE, Belgium; IT, Italy; DE, Germany; PT, Portugal; PL, Poland; EL, Greece; UK, United Kingdom; REU, rest EU.

TABLE 8: Inverse matrix 2007.

\begin{tabular}{|c|c|c|c|c|c|c|c|c|c|c|c|}
\hline & $\mathrm{NL}$ & ES & FR & $\mathrm{BE}$ & IT & $\mathrm{DE}$ & PT & PL & EL & UK & REU \\
\hline $\mathrm{NL}$ & 1.72267 & 0.02251 & 0.08597 & 0.45347 & 0.05109 & 0.94586 & 0.10963 & 0.47000 & 0.01403 & 0.67010 & 0.29166 \\
\hline ES & 7.29160 & 1.22545 & 0.54313 & 2.22485 & 0.24469 & 4.29244 & 1.49188 & 2.72100 & 0.06397 & 3.25458 & 1.37238 \\
\hline FR & 0.60625 & 0.01410 & 1.04419 & 0.40714 & 0.03262 & 0.42493 & 0.06588 & 0.25817 & 0.00731 & 0.26656 & 0.12427 \\
\hline $\mathrm{BE}$ & 1.02650 & 0.01671 & 0.10211 & 1.28364 & 0.03348 & 0.65199 & 0.07722 & 0.32236 & 0.01299 & 0.41885 & 0.18708 \\
\hline IT & 0.23077 & 0.00414 & 0.02214 & 0.07208 & 1.00747 & 0.19824 & 0.02213 & 0.09937 & 0.00438 & 0.12330 & 0.06792 \\
\hline $\mathrm{DE}$ & 0.70427 & 0.02137 & 0.04195 & 0.19067 & 0.02710 & 1.39118 & 0.14106 & 0.30508 & 0.01053 & 0.31694 & 0.14900 \\
\hline PT & 0.91546 & 0.15369 & 0.06966 & 0.27965 & 0.03087 & 0.53903 & 1.18719 & 0.34165 & 0.00803 & 0.41127 & 0.17238 \\
\hline PL & 0.06745 & 0.00134 & 0.00688 & 0.02248 & 0.00291 & 0.04051 & 0.00505 & 1.01981 & 0.00308 & 0.08024 & 0.04271 \\
\hline EL & 0.00244 & 0.00004 & 0.00016 & 0.00069 & 0.00008 & 0.00197 & 0.00022 & 0.00462 & 1.00003 & 0.00440 & 0.00199 \\
\hline UK & 0.07173 & 0.00128 & 0.00447 & 0.01924 & 0.00215 & 0.04005 & 0.00493 & 0.02039 & 0.00059 & 1.02811 & 0.01634 \\
\hline REU & 0.06632 & 0.00107 & 0.00456 & 0.03270 & 0.00231 & 0.04480 & 0.00514 & 0.03029 & 0.00105 & 0.02971 & 1.01200 \\
\hline
\end{tabular}

NL, Netherlands; ES, Spain; FR, France; BE, Belgium; IT, Italy; DE, Germany; PT, Portugal; PL, Poland; EL, Greece; UK, United Kingdom; REU, rest EU.

TABLE 9: Inverse matrix 2017.

\begin{tabular}{lccccccccccc}
\hline & NL & ES & FR & BE & IT & DE & PT & PL & EL & UK & REU \\
\hline NL & 1.9387 & 0.0293 & 0.1260 & 0.7894 & 0.1263 & 1.0925 & 0.0198 & 0.5585 & 0.0053 & 0.7270 & 0.4568 \\
ES & 7.0214 & 1.1219 & 0.6308 & 3.0707 & 0.5102 & 4.2069 & 0.3331 & 2.4324 & 0.0206 & 2.9344 & 1.7747 \\
FR & 1.5104 & 0.0289 & 1.1166 & 0.8947 & 0.1256 & 0.9588 & 0.0231 & 0.5575 & 0.0049 & 0.6016 & 0.3883 \\
BE & 1.4360 & 0.0241 & 0.1549 & 1.6050 & 0.1022 & 0.8774 & 0.0162 & 0.4370 & 0.0053 & 0.5573 & 0.3555 \\
IT & 0.1521 & 0.0031 & 0.0180 & 0.0794 & 1.0107 & 0.1333 & 0.0023 & 0.0761 & 0.0026 & 0.0785 & 0.0707 \\
DE & 0.3599 & 0.0072 & 0.0317 & 0.1960 & 0.0334 & 1.2079 & 0.0133 & 0.2169 & 0.0039 & 0.1731 & 0.1136 \\
PT & 0.3559 & 0.0544 & 0.0336 & 0.1568 & 0.0263 & 0.2129 & 1.0163 & 0.1263 & 0.0010 & 0.1534 & 0.0899 \\
PL & 0.0598 & 0.0045 & 0.0056 & 0.0266 & 0.0054 & 0.0380 & 0.0022 & 1.0193 & 0.0010 & 0.0348 & 0.0247 \\
EL & 0.0024 & 0.0001 & 0.0002 & 0.0010 & 0.0002 & 0.0016 & 0.0000 & 0.0011 & 1.0000 & 0.0009 & 0.0139 \\
UK & 0.1398 & 0.0033 & 0.0103 & 0.0582 & 0.0092 & 0.0795 & 0.0018 & 0.0411 & 0.0004 & 1.0529 & 0.0405 \\
REU & 0.1569 & 0.0026 & 0.0107 & 0.0692 & 0.0106 & 0.0944 & 0.0017 & 0.0506 & 0.0011 & 0.0614 & 1.0373 \\
\hline
\end{tabular}

NL, Netherlands; ES, Spain; FR, France; BE, Belgium; IT, Italy; DE, Germany; PT, Portugal; PL, Poland; EL, Greece; UK, United Kingdom; REU, rest EU.

works using genetic algorithm techniques, distributed programming, and colony-based algorithm models [43-46].

In the present work, the number of elements we have to deal with (the set of countries on which the interdependence analysis is performed) is small enough to rule out a minimum distributed path search model or one based on genetic algorithms. Instead, we will follow the idea of generating a triangulation path through permutations of rows/columns in the matrix directed by a cost calculation function.

This function is constructed in such a manner as to create a theoretical global minimum to a perfectly triangulated matrix, with all zeros above the diagonal. In reality, however, this state may not be attainable. The value of the cost function will give us, in this case, the level of triangulation achieved.

In order to develop this technique, a definition of the series of concepts in our problem is needed.

$\mathrm{U}$ is defined as the space of possible solutions to a problem $f$. of $f$.

$y \in \mathrm{U}$ is the possible solution that satisfies the conditions

$J(y)$ is defined as $\mathrm{U} \longrightarrow \mathrm{R}$ as a cost function of $f$ if it meets the following conditions: 
TABle 10: Triangulated matrix 2002.

\begin{tabular}{lccccccccccc}
\hline & FR & DE & UK & BE & EL & PL & PT & ES & IT & NL & REU \\
\hline FR & 1.00204 & 0.05834 & 0.01941 & 0.02343 & 0.00052 & 0.01074 & 0.00272 & 0.00174 & 0.00814 & 0.03673 & 0.02917 \\
DE & 0.01123 & 1.05952 & 0.03814 & 0.04035 & 0.00208 & 0.03469 & 0.02984 & 0.00222 & 0.00706 & 0.12321 & 0.01524 \\
UK & 0.00031 & 0.00203 & 1.00438 & 0.00073 & 0.00015 & 0.00679 & 0.00006 & 0.00001 & 0.00006 & 0.00169 & 0.05820 \\
BE & 0.00018 & 0.00224 & 0.00325 & 1.00092 & 0.00001 & 0.00161 & 0.00010 & 0.00009 & 0.00008 & 0.00323 & 0.00278 \\
EL & 0.00022 & 0.00016 & 0.00370 & 0.00024 & 1.00000 & 0.00010 & 0.00000 & 0.00000 & 0.00001 & 0.00004 & 0.00085 \\
PL & 0.04072 & 0.16167 & 0.13963 & 0.04321 & 0.00141 & 1.02594 & 0.00555 & 0.00125 & 0.00519 & 0.11798 & 0.02312 \\
PT & 0.00625 & 0.02802 & 0.03609 & 0.02485 & 0.00010 & 0.01386 & 1.01102 & 0.02359 & 0.00155 & 0.04391 & 0.01086 \\
ES & 0.26784 & 1.20549 & 1.55313 & 0.96260 & 0.00427 & 0.59621 & 0.47438 & 1.01532 & 0.06643 & 1.88948 & 0.46674 \\
IT & 0.01096 & 0.10651 & 0.14302 & 0.02852 & 0.00065 & 0.02241 & 0.00305 & 0.00029 & 1.00100 & 0.02140 & 0.05540 \\
NL & 0.03774 & 0.50196 & 0.29490 & 0.28758 & 0.00184 & 0.21442 & 0.01480 & 0.00227 & 0.02440 & 1.08153 & 0.09892 \\
REU & 0.00476 & 0.02282 & 0.07406 & 0.01027 & 0.00019 & 0.11018 & 0.00075 & 0.00015 & 0.00077 & 0.02055 & 1.03003 \\
\hline
\end{tabular}

NL, Netherlands; ES, Spain; FR, France; BE, Belgium; IT, Italy; DE, Germany; PT, Portugal; PL, Poland; EL, Greece; UK, United Kingdom; REU, rest EU.

(1) $\forall \mathrm{a}, \mathrm{b} \in \mathrm{U} \longrightarrow J(\mathrm{a})<J(\mathrm{~b}) \leftrightarrow \mathrm{a}$ is a better solution than $\mathrm{b}$ for problem $f$

(2) J, at least a minimum, corresponds to the optimal solution at the local level

The process of minimizing $J$ can be straightforward if it is defined as a derivable and continuous analytical function and there is an analytical procedure to determine the minimums of said function. Conversely, it can be an iterative procedure, when $J$ does not have an analytical form or there is no direct procedure to achieve its minimum values.

For the problem at hand, $U$ is defined as a set of possible solutions to the problem of triangulation of an input-output matrix $(f)$.

We define the cost function $J(y)$ on a matrix $y \in \mathrm{U}$ as the number of "zeros" above the main normalized diagonal according to the following expression:

$$
J(y)=1-\frac{n_{\text {zeros }}}{(1 / 2) \text { lines } * \text { columns }} .
$$

The cost function will define the level of triangulation of the matrix in each iteration. In order to select the best permutation, the cost function will be the discriminating element. This function has a maximum value of 1 for a perfectly triangulated matrix.

This cost function meets the conditions defined above although it requires the definition of the concept of zero in an input-output matrix.

In this work, the concept of zero is fundamental for the operation of the algorithm. There are general two possibilities:

(i) An absolute threshold based on the nature of the interdependence matrix data

(ii) A relative threshold related to the minimally significant interrelation factor for a study of these characteristics

For the present work, we have opted for the second option and define zero as that value of the matrix that is below the ten percentiles in an analysis of the distribution of values. This definition has been taken into account, compared to other possible ones (for example, a minimum threshold) as it allows the process of selecting interdependence values not relevant to the study to be automated.
The matrix triangulation process is as follows:

Step 1. Determine the threshold value of zero to triangulate on the matrix.

Step 2. Repeat this step a predetermined number of times or until a stop condition is met.

Step 2.1. Swap two rows of the array randomly.

Step 2.2. Calculate the value of J for the new matrix. Step 2.3. If the value of $J$ is less than that of the original matrix, replace the original with the permuted one.

The choice of rows and columns to be exchanged is methodical in order to test all possible permutations.

The stop criteria for Step 2 are, either by time, or a situation where the cost function does not decrease despite having tried all possible permutations. When this occurs, the gradient of function $J$ is close to zero, and a minimum has been found for the cost function.

The implementation of this process has been carried out using Matlab, as computing support to develop numerous tests, with different values for execution times and stop conditions and obtaining the results set out below.

\section{Results}

The results are displayed in Tables 10-12. The countries that lead the table are those that depend on the imports from other countries, while those at the base are clearly the exporting countries, and their activity is essential for the operation of the system.

For the year 2002 (Figure 2), France, Germany, and the United Kingdom are the main clients leading the table, while Spain, Italy, the Netherlands, and the rest of EU countries are located at the bottom, the majority of these being exporters.

For 2007 (Figure 3), the top of the table is headed by Poland, the United Kingdom, and the Netherlands and at the bottom by Spain, France, and Belgium.

For 2017 (Figure 4), the countries leading the table are Germany, Belgium, and France with the lower quadrant being occupied by the Netherlands, the United Kingdom, and Spain.

When comparing the years 2002 and 2007, a significant change is observed in the intra-EU tomato trade and how the 
TABLE 11: Triangulated matrix 2007.

\begin{tabular}{lccccccccccc}
\hline & PL & UK & NL & REU & IT & DE & PT & EL & ES & FR & BE \\
\hline PL & 1.72267 & 0.67010 & 0.01403 & 0.29166 & 0.05109 & 0.94586 & 0.10963 & 0.47000 & 0.02251 & 0.08597 & 0.45347 \\
UK & 0.07173 & 1.02811 & 0.00059 & 0.01634 & 0.00215 & 0.04005 & 0.00493 & 0.02039 & 0.00128 & 0.00447 & 0.01924 \\
NL & 0.00244 & 0.00440 & 1.00003 & 0.00199 & 0.00008 & 0.00197 & 0.00022 & 0.00462 & 0.00004 & 0.00016 & 0.00069 \\
REU & 0.06632 & 0.02971 & 0.00105 & 1.01200 & 0.00231 & 0.04480 & 0.00514 & 0.03029 & 0.00107 & 0.00456 & 0.03270 \\
IT & 0.23077 & 0.12330 & 0.00438 & 0.06792 & 1.00747 & 0.19824 & 0.02213 & 0.09937 & 0.00414 & 0.02214 & 0.07208 \\
DE & 0.70427 & 0.31694 & 0.01053 & 0.14900 & 0.02710 & 1.39118 & 0.14106 & 0.30508 & 0.02137 & 0.04195 & 0.19067 \\
PT & 0.91546 & 0.41127 & 0.00803 & 0.17238 & 0.03087 & 0.53903 & 1.18719 & 0.34165 & 0.15369 & 0.06966 & 0.27965 \\
EL & 0.06745 & 0.08024 & 0.00308 & 0.04271 & 0.00291 & 0.04051 & 0.00505 & 1.01981 & 0.00134 & 0.00688 & 0.02248 \\
ES & 7.29160 & 3.25458 & 0.06397 & 1.37238 & 0.24469 & 4.29244 & 1.49188 & 2.72100 & 1.22545 & 0.54313 & 2.22485 \\
FR & 0.60625 & 0.26656 & 0.00731 & 0.12427 & 0.03262 & 0.42493 & 0.06588 & 0.25817 & 0.01410 & 1.04419 & 0.40714 \\
BE & 1.02650 & 0.41885 & 0.01299 & 0.18708 & 0.03348 & 0.65199 & 0.07722 & 0.32236 & 0.01671 & 0.10211 & 1.28364 \\
\hline
\end{tabular}

NL, Netherlands; ES, Spain; FR, France; BE, Belgium; IT, Italy; DE, Germany; PT, Portugal; PL, Poland; EL, Greece; UK, United Kingdom; REU, rest EU.

TABle 12: Triangulated matrix 2017.

\begin{tabular}{|c|c|c|c|c|c|c|c|c|c|c|c|}
\hline & $\mathrm{DE}$ & $\mathrm{BE}$ & FR & EL & IT & REU & PT & PL & NL & UK & ES \\
\hline $\mathrm{DE}$ & 1.93870 & 0.45680 & 0.00530 & 0.72696 & 0.02929 & 0.12598 & 0.78945 & 0.12631 & 1.09254 & 0.01983 & 0.55853 \\
\hline $\mathrm{BE}$ & 0.15686 & 1.03731 & 0.00106 & 0.06138 & 0.00256 & 0.01074 & 0.06920 & 0.01063 & 0.09441 & 0.00172 & 0.05061 \\
\hline FR & 0.00236 & 0.01394 & 1.00002 & 0.00094 & 0.00006 & 0.00017 & 0.00105 & 0.00016 & 0.00165 & 0.00003 & 0.00108 \\
\hline EL & 0.13982 & 0.04048 & 0.00039 & 1.05286 & 0.00333 & 0.01031 & 0.05817 & 0.00921 & 0.07945 & 0.00176 & 0.04109 \\
\hline IT & 7.02141 & 1.77472 & 0.02064 & 2.93438 & 1.12189 & 0.63081 & 3.07072 & 0.51019 & 4.20686 & 0.33312 & 2.43237 \\
\hline REU & 1.51040 & 0.38826 & 0.00491 & 0.60161 & 0.02891 & 1.11663 & 0.89468 & 0.12558 & 0.95885 & 0.02306 & 0.55750 \\
\hline $\mathrm{PT}$ & 1.43599 & 0.35550 & 0.00532 & 0.55727 & 0.02412 & 0.15490 & 1.60500 & 0.10222 & 0.87738 & 0.01624 & 0.43697 \\
\hline PL & 0.15211 & 0.07073 & 0.00256 & 0.07852 & 0.00315 & 0.01800 & 0.07939 & 1.01073 & 0.13332 & 0.00226 & 0.07609 \\
\hline NL & 0.35994 & 0.11357 & 0.00385 & 0.17311 & 0.00722 & 0.03173 & 0.19605 & 0.03338 & 1.20790 & 0.01328 & 0.21695 \\
\hline UK & 0.35587 & 0.08991 & 0.00105 & 0.15338 & 0.05442 & 0.03362 & 0.15678 & 0.02628 & 0.21294 & 1.01627 & 0.12627 \\
\hline ES & 0.05984 & 0.02468 & 0.00102 & 0.03484 & 0.00448 & 0.00558 & 0.02663 & 0.00539 & 0.03799 & 0.00222 & 1.01926 \\
\hline
\end{tabular}

NL, Netherlands; ES, Spain; FR, France; BE, Belgium; IT, Italy; DE, Germany; PT, Portugal; PL, Poland; EL, Greece; UK, United Kingdom; REU, rest EU.

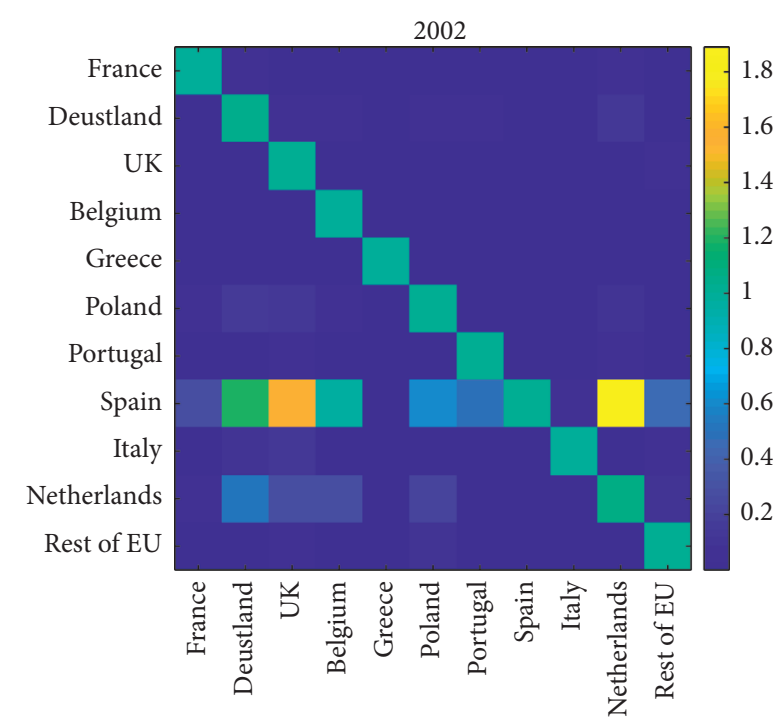

Figure 2: Triangulation of inverse matrix 2002. Source: own compilation.

crisis of $2017-13$ has caused a virtual return to the initial situation of 2002 in terms of the main customers and suppliers. In this sense, Germany, France, and Belgium stand out in the

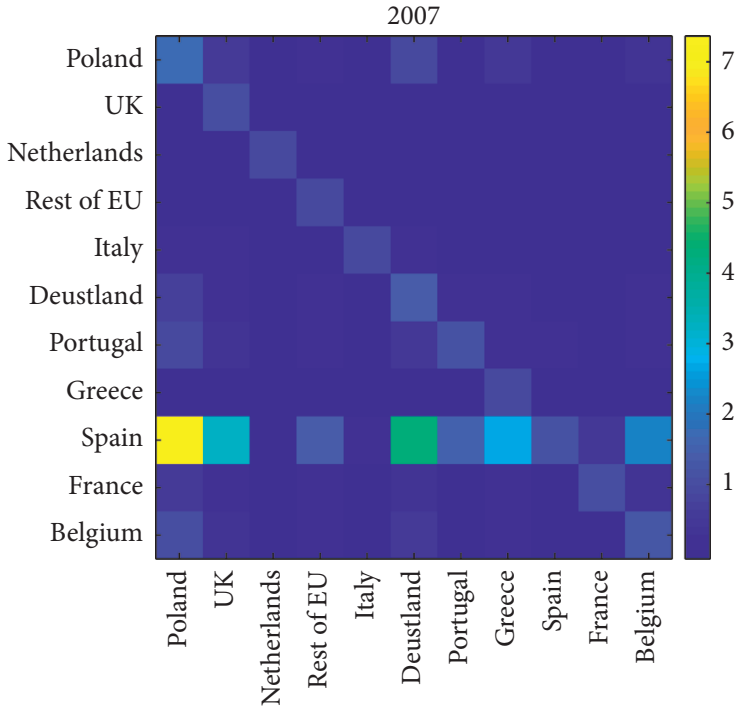

FIgURE 3: Triangulation of inverse matrix 2007. Source: own compilation.

upper part as importing countries, particularly during the winter season. At the base of the matrix, the Netherlands and Spain are shown to be principal intracommunity exporters. 


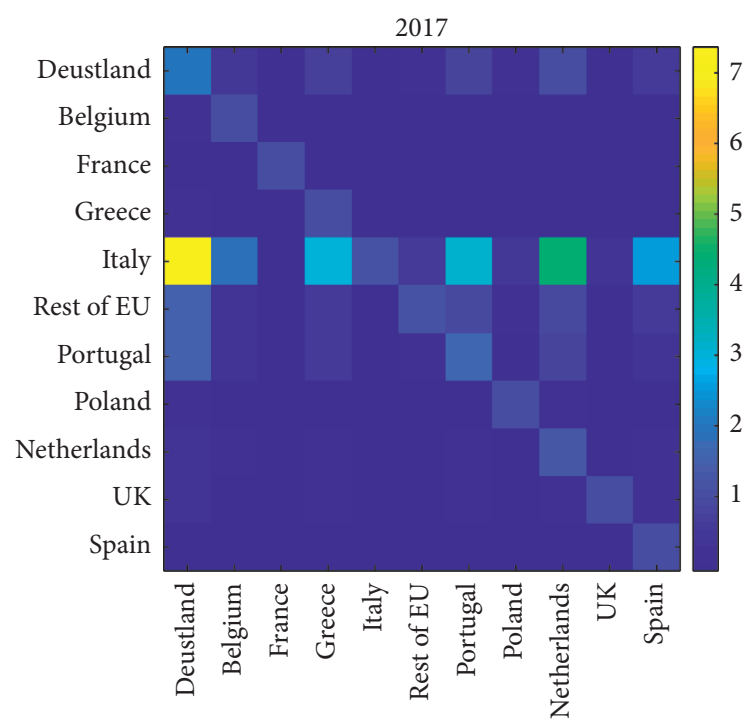

FIgURE 4: Triangulation of inverse matrix 2017. Source: own compilation.

\section{Discussion}

Traditional triangularizing methods that considery-Watanabe coefficients give acceptable results, but they present a series of limitations as discussed in the methodology section.

The implementation of pathfinding techniques is in line with other works such as that of Kondo [7] who proposes a new method to triangulate input-output tables based on mixed integer programs to compare the production structures of multiple economies.

The identification of key sectors/countries is essential to understand the operation of the system, as reflected in the works of Haji [16], Cassetti [17], Díaz et al. [18], and García Muñiz et al. [47]. In principle, the leading country in tomato exports within the EU is Spain; however, despite this fact, it is not considered to be a key player. The same cannot be said for the Netherlands and Belgium which are considered to be key players and operate efficiently with regard to their own trade transactions as well as in the reexportation of products from other countries. The question that arises and that should be identified is which process is the most profitable, production or commercialization. In the present case, the answer is clearly commercialization.

In the case of Spain, it is losing a great opportunity to act as an exporting country to Morocco. Despite being the lead exporter of tomatoes within the EU and a net exporting country, Spain is also becoming an import market. The reason for this is shift in purchasing patterns from traditional channels to that of large distributors: discount stores, supermarkets, and small independent stores are strongly committed to fresh food. Likewise, as reflected in the latest MERCASA study [48], these establishments, through their platforms, buy fresh products outside Spain. On the contrary, Table 13 shows how the Mercadona supermarket, regional chains such as IFA and Euromandi, and the Lidl discount store are becoming major market drivers as they continue to increase their market share.
TABLE 13: Market share of supermarket chains in Spain (2018-15).

\begin{tabular}{lcc}
\hline & $\begin{array}{c}\text { Market share } \\
(\%)\end{array}$ & $\begin{array}{c}\text { Variation } \\
(2018-2015)\end{array}$ \\
\hline Auchan group & 3.5 & 0.9 \\
Carrefour & 8.4 & -0.6 \\
Dia group & 7.5 & -1.7 \\
Eroski group & 5.3 & -1.0 \\
Lidl & 4.8 & 2.5 \\
Mercadona & 24.9 & 0.6 \\
Regional & 11.8 & 1.1 \\
supermarkets* & &
\end{tabular}

${ }^{*}$ Regional supermarkets do not include Eroski or Arbol supermarkets. Source: Kantar Worldpanel, Data to end of 2018.

\section{Conclusions}

The application of pathfinding techniques using a cost function is a consistent tool for the triangulation process of input-output tables. Consequently, the choice of a suitable cost function is essential to obtain a solution to triangulation.

The algorithm used for triangulation makes it possible to carry out the triangulation process by avoiding local minimums in the cost function by exploring time paths with a cost function value worse than the best found until a certain moment. This feature substantially improves the result. The size of this speculative scan slows the process by a factor dependent on the number of rows (columns) in the matrix.

Developing a table which displays the trade flows of intraindustrial tomato trade between the main countries of the European Union is a starting point for obtaining later the tables of technical coefficients and Leontief's inverse matrix. Likewise, comparing several years gives us an in-depth look at how these countries perform.

A structural analysis is essential to understand the interrelationships of a sector or an economy. The present case study has focused on hierarchy through triangulation. The sectors shown below the diagonal in the matrix are suppliers 
of the tomato sector, resulting in an increase in the final demand while those above the diagonal are considered to be customers in said sector.

The leading supplier countries are the Netherlands and Spain, with the former also acting as an export forwarder. As for customers, Germany stands out above the rest.

The tendency for the loss of power of wholesale markets at the expense of large distributors has been particularly noticeable in Spain which had traditionally been a net tomato exporter since it is the largest producer of fresh tomatoes and, but which in recent years, has seen the level of imports gradually increase.

\section{Data Availability}

The data used to support this study are free and publicly available from European Commission.

\section{Conflicts of Interest}

The authors declare that there are no conflicts of interest regarding the publication of this article.

\section{References}

[1] W. Leontief, The Structure of the American Economy, 1919-1939, Oxford University Press, Oxford, UK, 1941.

[2] H. Dinçer and S. Yüksel, "Financial sector-based analysis of the G20 economies using the integrated decision-making approach with DEMATEL and TOPSIS," in Emerging Trends in Banking and Finance, pp. 210-223, Springer, Berlin, Germany, 2018.

[3] S. Altuntas and T. Dereli, "A novel approach based on DEMATEL method and patent citation analysis for prioritizing a portfolio of investment projects," Expert Systems with Applications, vol. 42, no. 3, pp. 1003-1012, 2015.

[4] W.-S. Lee, A. Y. Huang, Y.-Y. Chang, and C.-M. Cheng, "Analysis of decision making factors for equity investment by DEMATEL and Analytic Network Process," Expert Systems with Applications, vol. 38, no. 7, pp. 8375-8383, 2011.

[5] C.-H. Cheng, J. Liou, and C.-Y. Chiu, "A consistent fuzzy preference relations based ANP model for R\&D project selection," Sustainability, vol. 9, no. 8, p. 1352, 2017.

[6] Q.-G. Shao, J. Liou, S.-S. Weng, and Y.-C. Chuang, "Improving the green building evaluation system in China based on the DANP method," Sustainability, vol. 10, no. 4, p. 1173, 2018.

[7] J. W. Foster and R. C. Higgins, "Modelling the quality of a manufacturing process using input-output analysis," International Journal of Production Research, vol. 10, no. 2, pp. 141-146, 1972.

[8] T. J. Mules, "Input-output analysis in Australia: an agricultural perspective," Review of Marketing and Agricultural Economics, vol. 511 pages, 1983.

[9] H. Verbeek, Innovative Clusters, Erasmus University, Rotterdam, Netherlands, 1999.

[10] M. Sonis, G. J. D. Hewings, and D. Guo, Industrial Clusters in the Input-Output Economic System, University of Illinois, Champaign, IL, USA, 2007.

[11] P. Midmore, M. Munday, and A. Roberts, "Assessing industry linkages using regional input-output tables," Regional Studies, vol. 40, no. 3, pp. 329-343, 2006.
[12] Y. Kondo, "Triangulation of input-output tables based on mixed integer programs for inter-temporal and inter-regional comparison of production structures," Journal of Economic Structures, vol. 3, no. 1, p. 2, 2014.

[13] R. Harthoorn, Production Chains, Central Bureau of Statistics, Netherlands, 1986.

[14] E.W. Henry, "A capacity growth input-output model with forward recursive solution," Energy Economics, vol. 17, no. 1, pp. 3-13, 1995.

[15] E. Velázquez, "An input-output model of water consumption: analysing intersectoral water relationships in Andalusia," Ecological Economics, vol. 56, no. 2, pp. 226-240, 2006.

[16] E. Dietzenbacher and E. Velázquez, "Analysing andalusian virtual water trade in an input-output framework," Regional Studies, vol. 41, no. 2, pp. 185-196, 2007.

[17] O. J. Asger, "Aggregation in input-output models: prices and quantities," Economic Systems Research, vol. 5, no. 3, pp. 253-264, 1993.

[18] F. Aroche-Reyes and A. S. García Muñiz, "Modelling economic structures from a qualitative input-output perspective: Greece in 2005 and 2010," Metroeconomica, vol. 69, no. 1, pp. 251-269, 2018.

[19] D. Lind, Value Creation and Structural Change during the Third Industrial Revolution, Lund University, Lund, Sweden, 2014.

[20] H. Zhang and X. Chen, “"An extended input-output model on education and the shortfall of human capital in China," Economic Systems Research, vol. 20, no. 2, pp. 205-221, 2008.

[21] J. A. Haji, "Key sectors and the Structure of Production in Kuwait - an input-output approach," Applied Economics, vol. 19, no. 9, pp. 1187-1200, 1987.

[22] M. Cassetti, "A new method for the identification of patterns in input-output matrices," Economic Systems Research, vol. 7, no. 4, pp. 363-382, 1995.

[23] B. Díaz, L. Moniche, and A. Morillas, "A fuzzy clustering approach to the key sectors of the Spanish economy," Economic Systems Research, vol. 18, no. 3, pp. 299-318, 2006.

[24] W. Leontief, Análisis Económico Input-Output, PlanetaAgostin, Barcelona, Spain, 1973.

[25] B. Korte and W. Oberhofer, "Triangularizing input-output matrices and the structure of production," European Economic Review, vol. 1, no. 4, pp. 482-511, 1970.

[26] B. Korte and W. Oberhofer, "Zwei Algorithmen zur Lösung eines komplexen Reihenfolgeproblems," Unternehmensforschung Operations Research-Recherche Opérationnelle, vol. 12, no. 1, pp. 217-231, 1968.

[27] J. Lamel, J. Richter, S. Teufel, and W. Bauer, "Triangulation," Economic Bulletin for Europe, vol. 23, pp. 59-75, 1971.

[28] Z. Drabek, "A comparison of technology in centrally-planned and market-type economies," European Economic Review, vol. 25, no. 3, pp. 293-318, 1984.

[29] Y. Fukuy, "A more powerful method for triangularizing input-output matrices and the similary of production structures," Econometrica, vol. 54, no. 6, pp. 1425-1433, 1986.

[30] E. C. Howe, "A more powerful method for triangularizing input-output matrices: a Comment," Econometrica, vol. 59, no. 2, pp. 521-523, 1991.

[31] O. Haltia, "A triangularization algorithm without ringshift permutation," Economic Systems Research, vol. 4, no. 3, pp. 223-234, 1992.

[32] F. A. Reyes, "Evolution of the productive structure of Mexico exercise for triangularizing the input-output matrix," Trimestre Económico, vol. 247, pp. 397-416, 1995. 
[33] T. F. M. Chang, L. C. Piccinini, L. Iseppi, and M. A. Lepellere, "The black box of economic interdependence in the process of structural change. EU and EA on the stage," Italian Journal of Pure and Applied, vol. 31, pp. 285-306, 2013.

[34] M. Grötschel, M. Jünger, and G. Reinelt, "Optimal triangulation of large real world input-output matrices," Statistische Hefte, vol. 25, no. 1, pp. 261-295, 1983.

[35] G. Östblom, "Use of the convergence condition for triangularizing input-output matrices and the similarity of production structures among Nordic countries 1970, 1980 and 1985," Struct Chang Econ Dyn, vol. 8, no. 1, pp. 481-500, 1997.

[36] C. Europea, "Statistics EU trade flows inside \& outside Europe," 2017, http://exporthelp.europa.eu/thdapp/display. $\mathrm{htm}$ ?page=st2fst_Statistics.html\&docType=main\&languageId=en.

[37] C. Europea, "Document de travail. Groupe de travails prévisions tomates," 2018, http://ec.europa.eu/agriculture/ fruit-and-vegetables/product-reports/tomatoes/index_en. htm.

[38] H. B. Chenery and T. Watanabe, "International comparisons of the structure of production," Econometrica, vol. 26, no. 4, pp. 487-521, 1958.

[39] E. Jahangard and V. Keshtvarz, "Turkey economies: a network theory approach," Iranian Economic Review, vol. 16, no. 32, pp. 45-58, 2012.

[40] J. Noceral and S. Wright, Numerical Optimization, Springer Science \& Business Media, Berlin, Germany, 2006.

[41] A. Antoniou and L. Wu-Sheng, Practical Optimization: Algorithms and Engineering Applications, Springer Science \& Business Media, Berlin, Germany, 2007.

[42] F. Audrino and G. Barone-Adesi, "Functional gradient descent for financial time series with an application to the measurement of market risk," Journal of Banking \& Finance, vol. 29, no. 4, pp. 959-977, 2005.

[43] K. Kulankara, S. Satyanarayana, and S. N. Melkote, "Iterative fixture layout and clamping force optimization using the genetic algorithm," Journal of Manufacturing Science and Engineering, vol. 124, no. 1, pp. 119-125, 2002.

[44] A. Richardson and E. Olson, "Iterative path optimization for practical robot planning," in Proceedings of the 2011 IEEE/RSJ International Conference on Intelligent Robots and Systems, pp. 3881-3886, IEEE, San Francisco, CA, USA, September 2011.

[45] J. Y. Hwang, J. S. Kim, S. S. Lim, and K. H. Park, "A fast path planning by path graph optimization," IEEE Transactions on Systems, Man, and Cybernetics-Part a: Systems and Humans, vol. 33, no. 1, pp. 121-129, 2003.

[46] J. Isern-González, D. Hernández-Sosa, E. Fernández-Perdomo, J. Cabrera-Gámez, A. C. Domínguez-Brito, and V. Prieto-Marañón, "Path planning for underwater gliders using iterative optimization," in Proceedings of the 2011 IEEE International Conference on Robotics and Automation, pp. 1538-1543, IEEE, Shanghai, China, May 2011.

[47] A. S. García, A. Morillas, and C. Ramos, "Key sectors: a new proposal from network theory," Regional Studies, vol. 42, no. 7, pp. 1013-1030, 2008.

[48] MERCASA, Informe del Consumo en España 2017, Ministerio de Agricultura, Madrid, Spain, 2018. 